\title{
ENTRE LA GUERRA Y LA POLÍTICA. UNA MIRADA COMPARATIVA DE LOS PROCESOS DE PAZ EN AMÉRICA LATINA: LOS CASOS DEL FMLN Y EL M-19 (1986-1992)
}

\author{
José David Moreno Mancera*
}

\begin{abstract}
Resumen: Hace 25 años la guerrilla salvadoreña del FMLN firmaba la paz con el gobierno del partido ARENA. Este acontecimiento se daba dos años después de la firma de acuerdos entre el M-19 y el partido liberal en aquel momento en el poder en Colombia. Tanto el FMLN como el M-19 dejarían las armas y pasarían a las urnas a través de la conformación de partidos políticos, uno con un éxito electoral rotundo y otro con un fracaso de la misma amplitud. El objetivo de este artículo es dar una mirada en perspectiva comparada a los dos procesos para comprender cómo se desarrollaron las negociaciones, en qué contextos se construyeron los respectivos acuerdos y, por último, qué bases solidificaron para los futuros procesos de participación política.
\end{abstract}

Palabras claves: Guerrilla; restablecimiento de la paz; América Latina; Colombia; El Salvador; historia; siglo XX.

\begin{abstract}
Salvadoran guerrilla of the FMLN signed the peace with the government of the ARENA party. This event occurred two years after the signing of agreements between the M-19 and the liberal party at that time in power in Colombia. Both the FMLN and the M-19 would drop their weapons and go to the polls through the formation of political parties, one with a resounding electoral success and another with a failure of the same extent. The aim of this article is to give a comparative perspective on the two processes in order
\end{abstract}

Fecha de recepción: 30/11/2017 - Fecha de aceptación: 01/01/2018

* Colombiano. Magíster en Historia Contemporánea y Relaciones Internacionales, Universidad de Lyon 3, 2009. Candidato a Doctor en Historia, Universidad Nacional de Colombia, 2017. Profesor Asociado del Departamento de Ciencia Política y Relaciones Internacionales de la Universidad de Bogotá Jorge Tadeo Lozano. Investigador del Observatorio de Paz de la misma universidad. Correo electrónico: josed.morenom@utadeo.edu.co 
to understand how the negotiations took place, in what contexts the respective agreements were built and finally what solidified bases for the future processes of political participation.

Keywords: Guerrilla; Peacemaking; Latin America; Colombia; El Salvador; History; Twentieth Century.

\section{Introducción}

El presente artículo es fruto de un trabajo de investigación que se ha venido desarrollando desde hace ya tres años con respecto a la guerra, el proceso de paz y la desmovilización de la guerrilla en El Salvador. Parte del desarrollo investigativo es dar una mirada comparativa entre este proceso centroamericano y el vivido por el Movimiento 19 de abril (M-19) en Colombia. Uno de los protagonistas centrales de este texto es la organización armada Farabundo Martí para la Liberación Nacional (FMLN). Creada a finales del año 1980 como consecuencia de la unión de cinco organizaciones guerrilleras menores, el FMLN plantea un esquema de guerra casi inédito en América Latina en un país que para 1980 escasamente llegaba a los 4 millones de habitantes. Es evidente que el otro protagonista será el M-19, una guerrilla emergente de las frustraciones electorales de 1970 en pleno régimen del Frente Nacional. El M-19 hará parte de la Coordinadora Guerrillera Simón Bolívar (CGSB), organización con una parca acción nacional debido a las fallas de diálogo entre las organizaciones subversivas. Lo cierto es que el M-19 dentro del espectro de las guerrillas colombianas es considerada, por una parte, una guerrilla urbana, pero más allá de eso una de las "organizaciones guerrilleras menores" en términos de hombres, armas y capacidad de combate. ${ }^{1}$ El objetivo del texto es ofrecer una mirada histórica detallada de los procesos de paz que llevaron a estas dos organizaciones a firmar la paz -en 1990 en el caso colombiano y en 1992 en el caso salvadoreño- en pleno contexto del final de la Guerra Fría. El interés por abordar estas dos organizaciones radica en cómo estas dejan las armas a través de procesos de negociación y posteriormente resultan conformando partidos políticos, siendo casos sui géneris en esa época para América Latina. ${ }^{2}$ Resulta interesante rastrear que en los procesos y las negociaciones de paz, así como en la definición de los

1 En términos de hombres y de armas para el año 1990, el M-19 contaba apenas con 800 combatientes. Esto en comparación a los más de 10 mil combatientes que sumaban las FARC, el ELN y el EPL, plantea al M-19 como una organización menor dentro del esquema de guerrillas colombianas. Ver, Eduardo Pizarro, Una democracia asediada: balance y perspectivas del conflicto armado en Colombia (Bogotá, Colombia: Editorial Norma, 2004), 128-142.

2 Resulta fundamental hacer la salvedad de casos como el venezolano que, en 1969, bajo la administración de Rafael Caldera, lanza una amnistía a la guerrilla del FALN y de allí se deriva una desmovilización de la guerrilla y su posterior reinserción a la vida civil. No obstante, esto no procede por la vía de un proceso de negociación de paz. Ver: Steve Ellner, De la derrota guerrillera a la política innovadora: el MAS (Caracas, Venezuela: Monte Ávila Editores, 1992), 195-200. 
Entre la guerra y la política. Una mirada comparativa de los procesos de paz en América Latina: los casos del FMLN y el M-19 (1986-1992)

acuerdos se construyen las bases de los futuros procesos políticos. Para el desarrollo de este texto se contó con el apoyo de una serie de entrevistas realizadas en San Salvador y algunas otras en Bogotá con actores directamente implicados en las negociaciones. También se desarrolla gracias a la consulta de algunos documentos de carácter oficial producto de las negociaciones en cuestión. La estructura de este artículo está basada en dos grandes partes que enuncian de forma detallada como se llevaron a cabo los procesos de paz de ambos países y se cierra con una conclusión que pretende hacer un breve balance comparativo de los dos procesos con el fin de comprender el porqué de la desmovilización de estas guerrillas y el cuándo, teniendo consideración del contexto de finalización de la Guerra Fría que se vivía en aquel momento.

\section{De la guerra civil de "alta intensidad" a la mesa de negociación: pro- ceso de paz en EI Salvador (1989-1992)}

Los acercamientos entre el gobierno salvadoreño y la guerrilla del FMLN fueron constantes casi desde el inicio mismo de la guerra en enero de 1981. Sin embargo, es preciso señalar que estos acercamientos fueron más evidentes a lo largo de las dos administraciones de los gobiernos de Napoleón Duarte (1984-1989) y resultaron definitivas en la administración de Alfredo Cristiani (1989-1994). Allí se puede señalar el primer encuentro realizado en octubre de 1984 entre las partes en disputa para comenzar a discutir escenarios de paz. No obstante, estos acercamientos fueron fallidos por una clara falta de voluntad de ambas partes y por un contexto tanto doméstico como internacional que no era favorable al diálogo. El gobierno de Duarte demandaba el abandono de las armas para iniciar la negociación, punto infranqueable para la guerrilla. A su vez, el FMLN exigía al gobierno la disolución del ejército y la policía como punto inicial de las negociaciones. Ante esta situación los avances fueron magros en medio de un contexto aún altamente beligerante y un gobierno que con el pasar de los días perdía pericia política y apoyos económicos. ${ }^{3}$ La Casa Blanca, bajo el mando de Reagan, de forma sutil apoyaba también esta postura. A pesar de la puesta en marcha de políticas como la de una reforma agraria fallida, que buscaba acercarse a los sectores de la izquierda, la administración Duarte fracasó rotundamente en la búsqueda de la paz. ${ }^{4}$

Luego de un lustro de enfrentamientos y de la puesta en marcha de lo que señala como poder dual ${ }^{5}$ por parte de la guerrilla, se vuelven a establecer los acer-

3 Francisco Ortiz, "El Salvador 1972-1992: conflicto social y memoria de un pensamiento político", en: Historia y debates sobre el conflicto armado salvadoreño y sus secuelas, (ed.) Jorge Juárez (San Salvador, El Salvador: Fundación Friedrich Ebert, 2014), 166.

4 Yvon Grenier, Guerres et Pouvoir au Salvador (Laval, Canadá: Les Presses de l'Université de Laval, 1994), 32.

5 Binford Leigh ilustra con el estudio del caso salvadoreño lo que él da a conocer como el poder dual, que puede ser de igual forma aplicable a otras guerrillas latinoamericanas. Este poder consiste en una suerte de 
camientos con el nuevo gobierno de ARENA. El año 1989 resulta crucial para los eventos marcados por la guerra de El Salvador. En lo esencial se registraba, por una parte, un evidente desgaste fruto del conflicto mismo y, por otra parte, se iba configurando un contexto internacional que iba señalando alternativas distintas a las de la lucha armada: "Ya cuando llegamos al 89 había una acumulación en la sociedad salvadoreña de apostarle a la paz. Había un movimiento muy fuerte de la sociedad civil, de sectores políticos y de la comandancia del FMLN apostándole y haciendo esfuerzos por llegar al final del derramamiento de sangre". ${ }^{6}$ Tal vez lo más paradójico es que hubiese sido de parte de ARENA y de D'Aubuisson de donde vinieran las principales iniciativas para desarrollar un proyecto de paz. ${ }^{7}$ Una vez Cristiani en el poder esta decisión se mantuvo. Resultaba un desafío para el gobierno, pues existían muchos sectores que se oponían a la paz negociada buscando por el contrario una guerrilla derrotada por la vía militar:

\begin{abstract}
"Nosotros llegamos al poder en 1989 gracias al trabajo desarrollado por Roberto D'Aubuisson que había logrado reunir importantes sectores de los empresarios, así como otros sectores democráticos. Nuestra proposición desde el primer momento fue la de firmar la paz con el FMLN en medio de un contexto interno muy complejo. Pero no se trataba simplemente de firmar una paz cualquiera sino una paz que pudiera permitir al Salvador encontrar el camino del desarrollo social y económico". ${ }^{8}$
\end{abstract}

El 9 de junio de 1989 cayó asesinado en San Salvador el ministro de la Presidencia José Rodríguez Porth, ${ }^{9}$ un personaje altamente conocido dentro de los sectores empresariales y comerciales del país, a tan solo una semana de su posesión y de haber iniciado la administración Cristiani. Rodríguez había sido encargado por el presidente Cristiani de llevar adelante los acercamientos y posteriores negociaciones con el FMLN. ${ }^{10}$ Su asesinato se presentaba entonces como la primera prueba de un proceso seriamente amenazado por diversas fuerzas

doble campo de lucha por parte de los rebeldes. De una parte, la lucha armada, pero, de otra, una lucha que no necesariamente es militar y que se da en las bases sociales de forma casi legal por intermedio de líderes sociales en diversos territorios. Ver: Binford Leigh, "El ejército revolucionario del pueblo de Morazán: la hegemonía dentro de la revolución salvadoreña", Estudios Centroamericanos (El Salvador): 625-626 (noviembre-diciembre, 2000).

6 Carlos Henríquez Consalvi. Miembro del FMLN. Director del Museo de Palabra y Memoria. Entrevista con el autor, San Salvador, 8 de junio de 2016.

7 Eduardo Sancho, Comandante del FMLN. Negociador de la paz en 1992. Entrevista con el autor, San Salvador, 10 de junio de 2016.

8 Alfredo Cristiani, Presidente de El Salvador entre 1989 y 1994. Firmante de la paz. Entrevista con el autor, San Salvador, 8 de junio de 2016.

9 Para reemplazar la temprana pérdida para la administración Cristiani de Rodríguez Porth, el presidente decide nombrar como jefe de los acercamientos y discusiones con la guerrilla al entonces ministro de Justicia, Óscar Santamaría. Óscar Santamaría, jefe del equipo negociador por parte del gobierno salvadoreño. Entrevista con el autor, San Salvador, 10 de diciembre de 2014 y 3 de junio de 2016.

10 Óscar Santamaría, entrevista con el autor. 
Entre la guerra y la política. Una mirada comparativa de los procesos de paz en América Latina: los casos del FMLN y el M-19 (1986-1992)

internas en El Salvador. El propio presidente Cristiani acusó de forma pública al FMLN de haber perpetrado este homicidio con el objeto de imponer sus condiciones en los acercamientos para el establecimiento de un proceso de paz. A pesar de esta acusación y la gravedad de los hechos, Cristiani se mantuvo en su voluntad de continuar con los acercamientos con la guerrilla. Para demostrarlo nombró en el mes de septiembre de ese mismo año la comisión negociadora de paz que estaría conformada por el exministro de Justicia Óscar Santamaría, dos representantes de las fuerzas armadas, el poeta y jurista David Escobar Galindo y el economista y exdirector del Banco Central Abelardo Torres. ${ }^{11}$

La búsqueda de la paz fue en fin de cuentas un proceso largo y dispendioso. Para lograr sentarse en la mesa de negociaciones fue necesaria la participación y el concurso de la ONU a través de su secretario general el peruano Javier Pérez de Cuéllar. El diálogo permanente con el gobierno y el FMLN fue relevante, prolongado, frágil y delicado. Sin esta intervención hubiera sido aún más complejo: "evidentemente hablamos de un proceso de paz en el cual sin la participación de las Naciones Unidas y los Estados Unidos hubiera fracasado". ${ }^{12}$ Estados Unidos cumple un papel determinante en el análisis del conflicto salvadoreño. Durante los ocho años de la administración Reagan, se destinaron más de 3 mil millones de dólares en temas militares para la lucha contra la guerrilla, otorgando magros resultados y dejando un elevado balance en materia de violación de Derechos Humanos. ${ }^{13}$ El giro más significativo lo va a enunciar la llegada de George Bush a la Casa Blanca (1989-1993). A pesar de ser republicano, la política hacia El Salvador se distanció mucho de la de Ronald Reagan y se tendieron puentes para incentivar una salida diferente a la militar. ${ }^{14}$

De esta forma se desarrolla el primer encuentro oficial entre la guerrilla del FMLN y el gobierno de El Salvador en la Ciudad de México en septiembre de 1989. Entre los voceros de la guerrilla se destacaron en este primer encuentro: Joaquín Villalobos (ERP), Salvador Samayoa (FPL), Roberto Cañas (PRTC) y Ana Guadalupe Martínez (ERP). ${ }^{15}$ Lo que se buscaba y se pretendía en este encuentro era la definición de una agenda de discusión, tal y como lo señalan la mayoría de protocolos de negociación de conflictos. Es de apreciar que los encuentros fueron auspiciados constantemente por las Naciones Unidas y el gobierno de los Estados Unidos. Al mes siguiente, en octubre, se efectuó en San José de Costa Rica una segunda ronda de acercamientos que seguía desarrollando

11 Óscar Martínez, Las negociaciones de los acuerdos de paz (San Salvador, El Salvador: Nuevo Enfoque, 2011), 143.

12 Salvador Samayoa, entrevista con el autor. San Salvador, 9 de diciembre de 2014 y 7 de junio de 2016.

13 Walter Lafeber, "The Reagan Administration and Revolutions in Central America", Political Science Quarterly (EE. UU.) 9, n. 1 (1984): 1-25, DOI: http://dx.doi.org/10.2307/2150256.

14 Manuel Montobbio, La metamorfosis de pulgarcito: transición politica y proceso de paz en El Salvador (Barcelona, España: Icaria Editorial, 1999), 108.

15 Roberto Cañas, Comandante del FMLN. Negociador de la paz en 1992. Entrevista con el autor, San Salvador, 9 de junio de 2016 . 
sus discusiones en torno a la definición de una agenda de negociaciones: "la propuesta que hizo el FMLN fue la de sentarse a la mesa sin cese al fuego y sin cese de hostilidades. Esto creó un marco sui generis de finalización del conflicto para El Salvador. La paz se hizo en este país en medio de la guerra" ${ }^{16}$ En medio de este delicado contexto se verían amenazados los diálogos como consecuencia del estallido de una bomba en la sede de FENASTRAS, el principal sindicato de trabajadores del país. En ese momento se cancelaron los diálogos por parte del FMLN que consideraba esto una seria provocación. ${ }^{17}$

El FMLN, al mismo tiempo que desarrollaba acercamientos con el gobierno no abandonaba la idea de insurrección popular, un imaginario fuertemente alimentado por la revolución sandinista de una década atrás. Joaquín Villalobos, comandante del ERP, era uno de los principales convencidos de que eso podría llegar a ser posible. ${ }^{18}$ Así, el FMLN entra en la ambigüedad y la dualidad que se debatía entre la negociación y la continuación de la lucha. Sobre todo, les inquietaba que el ambiente internacional que se vivía en aquel noviembre pudiera enviar señales al gobierno de Cristiani de debilidad y desventaja en la negociación:

"la percepción que se había venido generando sobre la guerrilla era que estábamos en proceso franco de declive. En los círculos militares se comienza entonces a difundir información de que todo es un asunto de tiempo y de que la guerrilla se está agotando y de que no tiene apoyos internacionales. Entonces nuestra convicción fue que con este nivel de percepción que hay sobre nosotros no puede haber una negociación razonable. Esto hay que cambiarlo y esto solo se puede cambiar mediante una ofensiva". ${ }^{19}$

Destacables eventos sucedidos en muy pocos días a finales de 1989 en El Salvador cambiaron las dinámicas y apreciaciones del proceso de paz. La ofensiva militar del 11 de noviembre por parte del FMLN, conocida como operación "Hasta el Tope", demostró la capacidad militar de la guerrilla. Cinco días después de estos hechos, seis sacerdotes jesuitas - cinco de ellos de nacionalidad española- fueron asesinados en las instalaciones de la Universidad Centroamericana (UCA). Entre los asesinados se encontraba el rector, Ignacio Ellacuría, quien en los meses precedentes había realizado un significativo trabajo de acercamiento con la guerrilla para establecer diálogos de paz. Esto le valió para ser señalado como cercano a la organización por parte de los cuerpos de inteligencia del ejército. Este evento tuvo un impacto muy fuerte en el ámbito nivel nacional

16 Óscar Santamaría, entrevista con el autor.

17 Paul Almeida, Olas de movilización popular: movimientos sociales en El Salvador (1925-2010) (San Salvador, El Salvador: UCA Editores, 2011), 294.

18 Ana Guadalupe Martínez, Comandante del FMLN. Negociadora de la paz en 1992. Entrevista con el autor, San Salvador, 9 de junio de 2016.

19 Facundo Guardado, Miembro del FMLN. Candidato a la presidencia en 1999. Entrevista con el autor, San Salvador, 8 de diciembre de 2014 y 2 de junio de 2016. 
Entre la guerra y la política. Una mirada comparativa de los procesos de paz en América Latina: los casos del FMLN y el M-19 (1986-1992)

como en el internacional y llevó al replanteamiento de la necesidad de impulsar los diálogos de paz de manera urgente. La noticia del asesinato de los jesuitas no había sido aún digerida cuando un avión de matrícula nicaragüense se accidentó en territorio salvadoreño. Se descubrió que este avión llevaba misiles antiaéreos de largo alcance y que estaban destinados al FMLN. Este hallazgo permitía pensar que la guerrilla estaba muy lejos de verse derrotada y en especial muy lejos de una voluntad de paz. Acto seguido se dio el asalto y toma del prestigioso hotel Sheraton en el cual se encontraba por esos días alojados el secretario general de la Organización de Estados Americanos y destacados oficiales del ejército de los Estados Unidos que se hallaban en tránsito hacia Panamá. Nuevamente se efectuaba una acción militar de alto impacto mediático. ${ }^{20}$ Ese complejo mes se cerró con el asesinato del consejero del presidente Cristiani para el proceso de paz José Guerrero. Es claro que dentro de todos estos eventos se manifestaban acciones de sabotaje al proceso de paz en sí. Las partes deberían continuar buscando la senda del diálogo a pesar de las provocaciones: "el conflicto había durado tanto tiempo y había producido tanto daño que se necesitaba un proceso de ganar confianza entre las partes y posteriormente un respaldo internacional que permitiese que la ejecución fuera verdaderamente exitosa". ${ }^{21}$

El coctel estaba más que listo para una explosión de orden social, político y militar. En los pocos días del mes de noviembre de 1989, tanto El Salvador como el mundo entero comprendieron la necesidad de una salida negociada del conflicto. La vía militar no era definitivamente la solución a la problemática. Durante la década de 1980 se aumentó el pie de fuerza militar del ejército y se entrenó a los oficiales de la fuerza armada. Con todo el apoyo posible por parte de los Estados Unidos, se hizo evidente que no era suficiente para encontrar pronto un vencedor en esta desgarradora guerra.

El balance luego de diez años de violencia exacerbada entre las partes es que no existen ni vencedores ni vencidos. Las acciones de noviembre de 1989 desarrolladas tanto por la guerrilla como por el ejército llevan a importantes reflexiones de ambas partes. Para finales de 1989, cuando los espectadores atónitos del mundo eran testigos de la caída del muro de Berlín, en El Salvador se llegaba a una situación que Zartman describe como "empate militar negativo". ${ }^{22}$ Esto quiere decir que las dos fuerzas en enfrentamiento, luego de un significativo desgaste, no han llegado a una posición, si se quiere, cercana de derrota del enemigo. En estas circunstancias se requiere que los contendientes no solo perciban dicho "empate", sino que también tengan una voluntad política para examinar la posibilidad de que la salida al conflicto no sea militar.

20 Salvador Samayoa, El Salvador: la reforma pactada (San Salvador, El Salvador: UCA Editores, 2002), 228-232.

21 Ana Guadalupe Martínez, entrevista con el autor.

22 William Zartman, "The Unfinished Agenda: Negotiating Internal Conflicts", en: Stopping the Killing: How Civil Wars End, (ed.) Licklider Roy (New York, EE. UU.: New York University Press, 1993), 48. 
El 6 de diciembre, Salvador Samayoa y Ana Guadalupe Martínez se reúnen con un delegado del secretario de las Naciones Unidas en Montreal y es allí donde la acción e intervención del organismo internacional es más clara. El gobierno de Cristiani y sus asesores se negaban a la participación de la ONU como mediadora del conflicto. Ellos se manifestaban más proclives por la OEA, dicho sea de paso, más manipulable por los Estados Unidos. Pero ante los eventos de noviembre, $\mathrm{y}$ ante el error tan significativo por parte del ejército salvadoreño de asesinar a los jesuitas, ${ }^{23}$ Pérez de Cuéllar disponía de una vía más amplia y cómoda para legitimar su posición como mediador. Para inicios de diciembre, tanto la guerrilla como el gobierno aceptan a la ONU como mediadora de los futuros procesos de paz. Así, el mes de noviembre funciona como una suerte de caja negra en la cual la dinámica del conflicto sufre amplias transformaciones.

A partir del 8 de diciembre se retoman los acercamientos entre las partes. El punto de partida por parte del gobierno era claro. Sin cese al fuego por parte de la guerrilla no habría oportunidad alguna de continuar los diálogos. Esta solicitud era interpretada por la guerrilla como una trampa, dado que el cese al fuego sería solo por parte de la guerrilla y el ejército salvadoreño estaría facultado para continuar sus operaciones. ${ }^{24}$

Para febrero de 1990 los avances eran mínimos en lo que se refiere a los acercamientos entre las partes. La casi totalidad de la comandancia vivía exiliada en Managua y el equipo negociador de la guerrilla era una placa móvil de dos o tres delegados que hacían un intenso trabajo diplomático desplegado especialmente en Centroamérica y los Estados Unidos. Lo cierto es que el FMLN no acepta el cese al fuego como condición sine qua non para el inicio de los diálogos. Pero a cambio y en muestra de buena voluntad ofrece una tregua al sabotaje económico, una de sus acciones más reconocidas. ${ }^{25}$ La postura del gobierno es tozuda, pero cada vez que esta era la posición siempre aparecía el apriete por parte de la Casa Blanca y el Secretario de Estado para aflojar estas posiciones. La firmeza del gobierno Cristiani, para este momento específico, venía especialmente medida como consecuencia de las elecciones que iban a tener lugar el 25 de febrero de 1990 en Nicaragua y que respondían a la continuidad o partida del régimen sandinista del poder. La óptica del gobierno salvadoreño era que, de perder los sandinistas, el FMLN resentiría una sensible pérdida de apoyo internacional y allí tendría desventajas para la negociación.

23 Luego de la muerte de los seis jesuitas, la posición de la Casa Blanca fue infranqueable e instó al gobierno de Cristiani a buscar una solución negociada del conflicto so pena de ver seriamente reducidas las ayudas económicas. Esta sería la "llave" internacional que permanentemente apretaba Washington para presionar el curso y desarrollo de los diálogos de paz.

24 Salvador Samayoa, Comandante del FMLN. Negociador de la paz en 1992. Entrevista con el autor, San Salvador, 7 de junio de 2016.

25 Eduardo Sancho, entrevista con el autor. 
Entre la guerra y la política. Una mirada comparativa de los procesos de paz en América Latina: los casos del FMLN y el M-19 (1986-1992)

Solo tres semanas después de analizar el impacto de la derrota sandinista a manos de la oposición, es posible retomar los acercamientos. Por tercera vez, Estados Unidos amenaza con suspender las ayudas económicas si el gobierno Cristiani no se sienta a la mesa de diálogo. De manera muy rápida se desenreda la situación y el gobierno no solo acepta dar inicio formal a los diálogos, sino también aceptar definitivamente la mediación del secretario Javier Pérez de Cuéllar. El 4 de abril de 1990, en Ginebra-Suiza, en medio del escepticismo total de las partes, se da la partida oficial de las negociaciones y de lo que se denominó un diálogo permanente de paz, firmando una declaración de las partes en presencia del secretario general de las Naciones Unidas Javier Pérez de Cuéllar: "cuando llegamos a Ginebra éramos conscientes del desafío que teníamos al frente. El gobierno Cristiani, a pesar de los actos de mala fe de la guerrilla, quería llegar hasta el final de las negociaciones. La expectativa era inmensa para todos los que estábamos presentes en Suiza". ${ }^{26}$

En mayo de 1990, en medio de fuertes combates por parte del ejército salvadoreño a la guerrilla del FMLN, se da la primera ronda de negociaciones en Caracas. ${ }^{27}$ El objetivo y propósito de esta primera ronda era un aspecto de carácter técnico pero esencial, a saber: la definición de una agenda y un calendario de negociaciones. ${ }^{28}$ El gobierno puso de inmediato sobre la mesa el cese al fuego como condición para definir luego una agenda. Los buenos oficios del delegado del Secretario General, Álvaro de Soto, permitieron destrabar este primer impasse: "lo curioso de esta reunión en Venezuela era que el gobierno no tenía planteamientos claros ni una agenda precisa. La guerrilla del FMLN era más estructurada en ese sentido y siempre fuimos muy organizados y metódicos. Nosotros éramos quienes llevábamos las propuestas y nosotros propusimos una agenda". ${ }^{29}$ Dentro de la agenda propuesta por el FMLN habían cuatro puntos centrales que podrían desglosarse en otros tantos. Allí estaban contenidos la desmilitarización del país, la democratización, una revisión al pacto económico social y desde luego, un cese al enfrentamiento armado. El 21 de mayo se firman finalmente los acuerdos de Caracas que logran establecer una agenda, ${ }^{30}$ pero con mayores dificultades para un calendario.

Dos semanas después los diálogos se trasladan a México. Como era evidente, el tema de la reforma de la Fuerza Armada sería central en la discusión y además sería el tema inicial. Empieza así un largo camino para dirimir un

26 Óscar Santamaría, entrevista con el autor.

27 Las acciones del ejército y las ofensivas de la guerrilla a lo largo de toda la negociación lo que demostraban era que el músculo militar era fundamental y decisivo en el pulso que las partes efectuaban en la mesa de negociación.

28 Óscar Martínez, Las negociaciones de los acuerdos de paz, 127.

29 Roberto Cañas, entrevista con el autor.

30 Acuerdos de Caracas: "Establecimiento de garantías y las condiciones necesarias para la reincorporación de los integrantes del FMLN: I Fuerza Armada; II Derechos Humanos; III Sistema Judicial; IV Sistema Electoral; V Reforma Constitucional; VI Problema Económico Social; VII Reincorporación de los integrantes del FMLN; VIII Verificación por las Naciones Unidas". Óscar Martínez, Las negociaciones de los acuerdos de paz, 153. 
tema altamente espinoso teniendo en cuenta que los militares habían detentado el poder entre 1932 y 1979 y habían triplicado sus efectivos y el presupuesto a lo largo de la guerra contra la guerrilla. Esta situación resultaba tensa para el presidente Cristiani quien recibía mucha presión por parte de las filas militares que estaban siempre atentas de las negociaciones que se daban alrededor del tema de la fuerza armada. ${ }^{31}$ Como era de esperarse, ante posiciones tan antagónicas la ronda se cierra sin acuerdo ni aproximación alguna. Las discusiones se van a trasladar a San José de Costa Rica. Allí, Álvaro de Soto plantea que se discutan otros temas alternativos al asunto de la fuerza armada con el fin de poder avanzar en el proceso. Es así como entra en escena otro de los temas más sensibles: los derechos humanos. Acerca de este tema hubo avances sustanciales que permitían destrabar por primera vez la negociación. A través de estos acuerdos se esperaba detener la tortura, el secuestro, las desapariciones forzosas, defender la figura del hábeas corpus, la libertad de prensa y especialmente el desmonte de los esnes de la muerte. ${ }^{32}$ Con estos acuerdos se le quería dar un alto inmediato a la sistemática violación de los derechos humanos en El Salvador. Junto a estas propuestas, nació también la Misión de las Naciones Unidas para El Salvador (ONUSAL), cuya misión central era la de verificar justamente que lo acordado en San José se cumpliera. En realidad, una verificación por parte de las Naciones Unidas era la única garantía que permitía el cumplimiento real de lo acordado:

\begin{abstract}
"con respecto a la ONUSAL recuerdo que el gobierno quería que esta se implementara solo después de la firma total de los acuerdos. Claro, era difícil para el gobierno someterse a una fiscalización internacional y en caso de ser necesario necesitaba hacer tiempo pues sabía que sus fuerzas armadas eran claras violadoras de derechos humanos. Pero al fin de cuentas creo que hubo un avance importante al respecto pues la ONUSAL se implementó en medio de los acuerdos y eso era ya una ganancia, significaba que el gobierno estaba cediendo y eso garantizó al fin de cuentas el final de las violaciones que fueron tan sistemáticas a lo largo de una década". ${ }^{33}$
\end{abstract}

El de San José sería entonces el primer acuerdo sustancial que se llevaría a cabo en la negociación. Este punto gozaba de amplia significación, dado que el saldo en esa materia era por de más vergonzoso al contar más de setenta mil víctimas fatales en la guerra. ${ }^{34}$

31 Samayoa, 279.

32 Donald W. Jackson, Michael Dodson y Laura Nuzzi O’Shaughnessy, "Protecting Human Rights: The Legitimacy of Judicial System Reforms in El Salvador", Bulletin of Latin American Research (EE. UU.) 18, n. 4 (1999): 403-421, DOI: http://dx.doi.org/10.1111/j.1470-9856.1999.tb00142.x.

33 Francisco Jovel, Comandante del FMLN. Negociador de la paz en 1992. Entrevista con el autor, San Salvador, 8 de junio de 2016.

34 Óscar Martínez, El Salvador: Los acuerdos de paz y el informe de La Comisión de la Verdad (San Salvador, El Salvador: Nuevo Enfoque, 2007), 160-161. 
Entre la guerra y la política. Una mirada comparativa de los procesos de paz en América Latina: los casos del FMLN y el M-19 (1986-1992)

Sin embargo, lo que vendría después, como se ha mencionado, sería ya más complicado. El arranque de las negociaciones estuvo marcado por el tema de las fuerzas armadas: "al inicio, las peticiones del FMLN eran inaceptables, por ejemplo, una de sus peticiones originales era que había que hacer desaparecer a las fuerzas armadas". ${ }^{35} \mathrm{El}$ cese al fuego seguía también siendo materia de álgidos debates. La fuerza armada y el cese al fuego eran simplemente puntos nodales sin soluciones claras en la ronda de San José. Estos resultaron ser temas bastante complejos y con una fuerte resistencia por parte de las fuerzas armadas, tanto en El Salvador como por parte de sus dos representantes en la mesa de negociación. El tema fue tan duro de manejar que según sus protagonistas, en más de una ocasión se estuvo a punto de romper con los diálogos. ${ }^{36}$

Para octubre de 1990 se efectúa una nueva ronda en México. Por primera vez el FMLN cede ante la solicitud y demanda de un cese al fuego. La guerrilla acepta determinar el 31 de mayo de 1991 como fecha límite para tal efecto, pero solo con la condición de avanzar en los temas más complejos de la agenda. La negociación vuelve a estancarse en laberintos sin salida. Los meses que siguen van a desarrollar una dinámica muy similar. Desde la firma de los acuerdos de San José, la mesa de negociación no volvió a acordar nada sustancial en el resto de 1990. Solo es interesante señalar que en noviembre de 1990, un año después de la operación "Hasta el Tope", el FMLN vuelve a lanzar una ofensiva de menor amplitud pero de mayor resonancia en el seno de la comunidad internacional que no reparó en hacerles fuertes observaciones a los negociadores de la guerrilla. ${ }^{37}$

En abril de 1991, aun en México, luego de una breve estancia en Caracas que no rindió efecto alguno, se propone trabajar en equipos de tres representantes por parte del gobierno y tres por parte de la guerrilla con el fin de hacer negociaciones simultáneas y avanzar en temas centrales. ${ }^{38}$ Además de ello, se propone recuperar el tiempo que se ha perdido en los meses precedentes en los cuales no han emergido acuerdos significativos. Lo cierto es que dos grandes puntos vuelven a convertirse en temas articuladores. Por una parte, un equipo discute dos reformas de fondo para el Estado salvadoreño: la reforma de la fuerza armada y la reforma constitucional. ${ }^{39}$ Por otra parte, otro de los equipos va a discutir el espinoso tema del cese al fuego. Al final de cuentas fue Álvaro de Soto, representante de Pérez de Cuéllar y pieza maestra de las negociaciones, quien intervino en estos días haciendo propuestas a las dos partes y ajustes significativos a las propuestas de las

35 Alfredo Cristiani, entrevista con el autor.

36 Roberto Cañas, entrevista con el autor.

37 Salvador Samayoa, entrevista con el autor.

38 Óscar Martínez, Las negociaciones de los acuerdos de paz, 176.

39 La reforma constitucional preveía diversos y amplios temas tales como: reforma a la justicia, reforma electoral, defender el derecho a la rebelión -artículo 248-, reforma agraria, modificaciones a la policía nacional, instauración del plebiscito como una reforma democrática y que los partidos políticos no sean el único mecanismo de representación popular tal como lo establecía la Constitución de 1983. 
partes para lograr establecer consensos. Era de suma importancia que la Asamblea Legislativa hiciera las reformas a la Constitución antes del 30 de abril, día en que terminaba la legislatura. Dado que las reformas a la Constitución requieren de dos legislaturas, de no aprobarse antes de la fecha establecida, las reformas tendrían que esperar hasta 1994 para ser aprobadas. ${ }^{40}$ Los acuerdos se firmaron en México el sábado 27 de abril, a 72 horas de terminar la legislatura. Maratónicas jornadas de discusión esperaban a la Asamblea en San Salvador del 28 al 30 de abril para poder hacer las reformas a la constitución. Es de destacar la disciplina de los partidos políticos y el apoyo dado a las reformas que les pudieron dar continuidad a los acuerdos. No obstante, aún quedaban asuntos pendientes que ya para nadie eran extraños: reformas a la fuerza armada y cese al fuego: "en realidad fueron diálogos de paz siempre realizados en situaciones extremas y bajo la presión constante de los tiempos políticos y administrativos". ${ }^{41}$

El 25 de mayo de 1991, cuando la presión de los tiempos legislativos de El Salvador había bajado, y una vez que la legislatura 1991-1994 había ratificado las reformas a la Constitución, las partes se volvieron a sentar a la mesa para tratar temas que se venían aplazando varios meses atrás. Para esta fecha las partes se instalan nuevamente en Venezuela abriendo una nueva ronda de discusiones. Ronda que dicho sea de paso se vio enmarcada por una gran ofensiva militar del ejército en el ámbito nacional en El Salvador. ${ }^{42}$ Este factor se convierte en argumento para la guerrilla en querer seguir aplazando la idea de un cese al fuego por parte de los insurgentes. Como en ocasiones anteriores, el FMLN - pero en especial el comandante Joaquín Villalobos- decidió para esta ronda poner sobre la mesa una solución al impasse de la reforma de la fuerza armada. ${ }^{43}$ Ante la negativa de los negociadores y de las resistencias militares en El Salvador de cara a las reformas propuestas, la guerrilla propone la fórmula de la fusión de los dos ejércitos - fuerza armada y guerrilla- . Fórmula que ciertamente deja perplejos a los negociadores del gobierno que ven en esta propuesta algo más que insensato. ${ }^{44}$

Con el fin de evadir y aplazar una vez más tan tensa discusión, las partes acuerdan comenzar a debatir sobre el tema de la Policía Nacional. Esta Policía dependía, hasta las negociaciones, directamente del Ministerio de Defensa y del ejército nacional. No obstante, hablar de reformas a la Policía era más viable que las reformas al ejército y la fuerza armada en general. La propuesta central es acabar con los tres cuerpos de seguridad -Policía Nacional, Guardia Nacional y Policía de Hacienda- y crear uno nuevo con un fuerte componente civil en sus directivas y con una doctrina renovada. ${ }^{45}$

40 Constitución de la República de El Salvador; 1983, art. 248.

41 Facundo Guardado, entrevista con el autor.

42 Samayoa, 383.

43 Ana Guadalupe Martínez, entrevista con el autor.

44 Óscar Santamaría, entrevista con el autor.

45 Óscar Martínez, El Salvador: Los acuerdos de paz..., 36. 
Entre la guerra y la política. Una mirada comparativa de los procesos de paz en América Latina: los casos del FMLN y el M-19 (1986-1992)

Estas discusiones tomarán varias semanas y no podrán ser agotadas en Venezuela. La mesa se traslada una vez más a Nueva York en el mes de septiembre. El tema de la Policía sigue en el centro de las discusiones. A pesar de que el gobierno acepta una reforma de fondo, la discusión se atasca en cuanto a la idea de la guerrilla de mantener cuotas de participación en la nueva institución. En dicho sistema de cuotas, tantos expolicías como desmovilizados de la guerrilla tendrían condiciones igualitarias de acceso en tanto que agentes de seguridad de esta nueva policía. ${ }^{46} \mathrm{~A}$ pesar de todo, son destacables los avances de esta ronda. Lo más significativo es que llegaron a los primeros acuerdos en temas de fuerza armada, resaltando los aspectos de depuración, reducción, doctrina y sistema educativo. En cuanto a la Policía también se evidenciaron avances notables destrabando los principales puntos de disputa. Para sumar a todos estos avances que habían tomado meses de discusión, se acordó que el cese al fuego solo procedería después de haber finalizado y firmado todos los acuerdos. Estamos aquí ante la recta final de los diálogos y las negociaciones. Las semanas finales de 1991 no fueron ajenas a la presión, los puntos de inflexión y de nuevo la lucha y carrera contra el reloj. ${ }^{47}$ En octubre de 1991, en México se acordó finalmente la disolución de los antiguos cuerpos de seguridad o policías que tantas víctimas cobraron en el país, al mismo tiempo que simbolizaban todo un esquema de impunidad. ${ }^{48}$ Ante los avances, el FMLN decide decretar una tregua unilateral como signo de buena fe y confianza. Confianza que es burlada a través de una nueva ofensiva del ejército desarrollada en el mes de noviembre de 1991. A esta ofensiva, la Casa Blanca recurre una vez más a la presión económica y política para obligar a retroceder al gobierno de Cristiani y a sus fuerzas armadas. Ante las dificultades y las tensiones que van anunciando no solo el fin del año, sino de la gestión de Pérez de Cuéllar como Secretario General, este último decide trasladar las negociaciones directamente a Nueva York en la sede de las Naciones Unidas. ${ }^{49}$ Allí se va a discutir en especial la adscripción de la Policía a un ministerio que no sea el de la defensa ni menos aún del interior, por ser este aún fortín de los militares. También se discute lo que será el nuevo cuerpo de inteligencia que pueda reemplazar el obsoleto y anquilosado organismo vigente hasta la fecha. A finales de diciembre se logran destrabar las partes más sensibles de los temas pendientes de la agenda gracias, en cierta medida, a la pericia del Secretario General y su asesor personal, pero sin duda alguna a la presión constante del Departamento de Estado y de su subsecretario Bernard Aronson.

46 José David Moreno Mancera, "Proceso de paz e incorporación de ex combatientes salvadoreños a la fuerza pública: experiencias y lecciones para Colombia”, en: Experiencias internacionales de paz, (ed.) Miguel Barreto (Bogotá, Colombia: Universidad Jorge Tadeo Lozano, 2016), 112.

47 Francisco Jovel, entrevista con el autor.

48 Moreno Mancera, 114.

49 Óscar Santamaría, entrevista con el autor. 
Finalmente se llegó a un acuerdo in extremis el 31 de diciembre de 1991 en la sede de las Naciones Unidas en Nueva York:

"verdaderamente se trataba de un final extremo. Después de muchos días de negociación no llegábamos a encontrar salidas a temas muy espinosos. El 31 de diciembre la presión del Secretario General era máxima. Él quería terminar hacia las 5 de la tarde. Sin embargo, a media noche no habíamos aún encontrado salidas claras. Decidimos entonces detener el reloj y continuar con las negociaciones. Dijimos al mundo que habíamos terminado a media noche pero en realidad tuvimos que haber terminado hacia las $2 \mathrm{de}$ la mañana. Esa fue la locura de las negociaciones". ${ }^{50}$

Al final de cuentas se encontraron soluciones y salidas al tema. Se lograron firmar los acuerdos dentro de unas condiciones por de más complejas, especialmente en lo que a tiempo se refiere. En el primer tema de la agenda lo que se concluyó fue la necesaria reducción del número de efectivos, la supresión de los Batallones BIRI, la supresión de las tres policías ya mencionadas y convertirlas en una sola, terminar con la práctica del reclutamiento forzoso y en especial se solicitó al gobierno colaborar en la desarticulación de los cuerpos paramilitares, principales encargados de efectuar la represión en las áreas rurales. ${ }^{51}$ Además de ello, tanto la escuela militar del ejército como la futura escuela de formación de policías estarían regidas por unos comités cívico-militares que determinarían las políticas académicas y curriculares de las instituciones. Otro de los grandes acuerdos que se pueden destacar es el tema electoral y su reforma, la cual hacía también parte de los puntos centrales de la agenda:

"en El Salvador existía antes de los acuerdos un consejo electoral compuesto por tres personas designadas por el presidente. A este consejo no tenían acceso los partidos de oposición. Está de más decir que ellos hacían lo que se les daba la gana con las elecciones. Ese consejo se transformó en el Tribunal Superior Electoral que conocemos ahora en el cual tienen cabida todos los partidos políticos". ${ }^{2}$

En materia de justicia también se encontraba un sistema amañado y controlado siempre por el Ejecutivo. Antes de 1992, los magistrados eran elegidos por mayoría simple. De suerte que el partido mayoritario en la Asamblea Legislativa siempre lograba nombrar a los magistrados. Esta metodología de elección se desarticuló imponiendo un nuevo sistema en el que los partidos minoritarios también tuvieran espacio de participación. ${ }^{53}$ En temas de justicia transicional se

50 Roberto Cañas, entrevista con el autor.

51 Óscar Martínez, El Salvador: Los acuerdos de paz..., 173-188.

52 Salvador Samayoa, entrevista con el autor.

53 Óscar Martínez, El Salvador: Los acuerdos de paz..., 173-188. 
Entre la guerra y la política. Una mirada comparativa de los procesos de paz en América Latina: los casos del FMLN y el M-19 (1986-1992)

planteó la posibilidad de una ley de amnistía general que en líneas generales les abriera el espacio a los desmovilizados de la guerrilla de participar en política:

"el FMLN quería ser partido político, por lo tanto, todos sus dirigentes, para poder participar en política al interior del país, no tenían que tener delitos que fueran perseguidos por la justicia y por el otro lado las fuerzas armadas jamás iban a dejar que se firmara un acuerdo de paz si en el texto del acuerdo llevaba implícito que ellos, por actos cometidos durante el conflicto, pudiesen ser llevados a la justicia y encarcelados". ${ }^{54}$

\section{La paz durante los años de la administración Barco 1986-1990: de la crisis de los acuerdos de La Uribe a la compleja desmovilización del M-19}

La toma del Palacio de Justicia en noviembre de 1985 marcó de forma contundente el cierre de la administración del presidente conservador Belisario Betancur (1982-1986). Con este acto provocado por el M-19 la continuidad de cualquier tipo de diálogo de paz era más que compleja y carecía en gran medida de legitimidad ante la sociedad en sí misma. La inquietante y aguda crisis con la que se llega al año 1986 deja una impronta representativa en el periodo electoral de ese año convirtiendo, de esta forma, la paz en un tema ineludible de campaña para la mayoría de los candidatos. ${ }^{55}$ Las cenias del Palacio de Justicia no fueron el único elemento que marcaban los ritmos de la historia nacional para ese momento. Fenómenos como el ascenso del narcotráfico y la sensible evolución de grupos de carácter paramilitar enrarecían el ambiente social y político.

Como hemos expuesto, la paz será uno de los derroteros del gobierno de Barco. Sin embargo, hablar de paz luego del rotundo fracaso desarrollado por el presidente Betancur resultaba más que complejo y desafortunado. Estas iniciativas despertaban especialmente incertidumbre en amplios sectores políticos, algunos sectores sociales, pero sobre todo en las lides militares que desde varios años atrás habían representado una real resistencia a la paz. El mismo presidente Barco, en aras de desprenderse y demarcar sus iniciativas de paz de las iniciativas de su predecesor lanza sendas críticas a la metodología utilizada para allanar el camino de la paz. ${ }^{56}$ Uno de los primeros objetivos que se traza el presidente es entonces desestructurar el modelo de comisiones de paz y asumir, en tanto jefe de Estado, de una manera más directa, los acercamientos con los alzados en armas y

54 Ana Guadalupe Martínez, entrevista con el autor.

55 Socorro Ramírez, Actores en conflicto por la paz: el proceso de paz durante el gobierno Betancur (19821986) (Bogotá, Colombia: Siglo XXI Editores, 1988), 267.

56 Álvaro Villarraga, Se inician acuerdos parciales: pacto político con el M-19 (Bogotá, Colombia: Fundación Cultura Democrática, 2009), 229. 
las posibilidades de diálogo de paz. ${ }^{57}$ Ahora bien, es importante señalar que desde el primer momento, la administración Barco se lanzó en la línea opuesta de Betancur. Es decir, que la paz se concreta con grupos que demuestren una voluntad seria al respecto. Por ello, la tregua de orden unilateral se comienza e erigir como condición sine qua non para los acercamientos y los diálogos. Los objetivos de Barco son la desmovilización al menor costo posible y sin la necesidad de verdaderas reformas estructurales de fondo en materia política e institucional..$^{58}$

El presidente Barco se preocupó fundamentalmente por hacer acercamientos con las FARC en un primer momento de su mandato. Sin embargo, dichas aproximaciones resultaron ser poco efectivas y sin ningún tipo de resultados. Los acercamientos con los demás grupos guerrilleros eran muy escasos e incluso inexistentes. Solo se pueden destacar algunas aproximaciones con el M-19 a comienzos de $1987 .{ }^{59}$ No obstante, esta guerrilla parecía seguir operando en la misma dinámica que había trabajado a lo largo del gobierno de Betancur, es decir, con iniciativas políticas de una parte, pero al mismo tiempo iniciativas del orden militar que lograban desconcertar al gobierno por momentos. ${ }^{60}$ Pero lo que se puede percibir es que el gobierno de Barco en realidad había lanzado toda su apuesta a acercamientos y negociaciones de paz tanto con el M-19 como con las FARC. Acerca de los otros grupos había poca o ninguna esperanza ${ }^{61}$ En este contexto nace la Coordinadora Guerrillera Simón Bolívar (CGSB), en septiembre de 1987. En realidad, no era una iniciativa nueva por parte de las organizaciones guerrilleras. En años anteriores había existido la Coordinadora Nacional Guerrillera, CNG, que tuvo reales inconvenientes para efectuar un diálogo coordinado por parte de los comandantes de cada una de las organizaciones. Los esfuerzos por desarrollar este tipo de ejercicio pueden percibirse como una copia del modelo centroamericano dentro de los cuales se destacan tanto el FMLN salvadoreño como la Unión Revolucionaria Nacional Guatemalteca (URNG).

Luego de más de un año de gobierno del presidente Barco, los avances en temas de paz eran casi nulos. Los diálogos y acercamientos con las guerrillas están en su peor momento y sin logros destacables que el presidente pudiera presentar a la opinión pública, a la institucionalidad y a los partidos políticos. Al mismo tiempo el terrorismo desatado por los narcotraficantes acorrala de forma permanente las instituciones del Estado. Las guerrillas continúan con sus hostigamientos en diferentes puntos del territorio sin que las fuerzas armadas puedan

57 Rafael Pardo, De primera mano Colombia 1986-1994: entre conflictos y esperanzas (Bogotá, Colombia: Grupo Editorial Norma, 1996), 74-75.

58 Eduardo Pizarro, Cambiar el futuro: historia de los procesos de paz en Colombia (1981-2016) (Bogotá, Colombia: Debate, 2016), 83.

59 Héctor Pineda, entrevista con el autor, Bogotá, 7 de noviembre de 2015.

60 Pizarro, Cambiar el futuro..., 112.

61 Pardo, 99. 
Entre la guerra y la política. Una mirada comparativa de los procesos de paz en América Latina: los casos del FMLN y el M-19 (1986-1992)

controlar la situación. ${ }^{62}$ Por último, los grupos paramilitares y la guerra sucia se apoderan del país y se desarrolla una guerra sin cuartel contra los movimientos y líderes sociales y políticos. ${ }^{63}$ Las críticas llueven sin reposo sobre el gobierno y el consejero Ossa renuncia a su cargo para convertirse en candidato del Partido Liberal para la Alcaldía de Bogotá. Su reemplazo, Rafael Pardo, asume la tarea de continuar la búsqueda de la paz en un escenario de importantes fuerzas en contra o escépticas de esta. ${ }^{64}$

En enero de 1988 la administración efectúa una suerte de "fuga hacia adelante" en un momento políticamente difícil, dado que en marzo de ese mismo año se realizaban unas elecciones muy importantes que ponían a prueba la reforma constitucional que le daba vía libre a la descentralización en Colombia. Estas elecciones se harían entonces en un contexto altamente bélico, violento y crítico. Es así como desde la sede del gobierno, de parte de los asesores y funcionarios cercanos del presidente, emerge la iniciativa de poner en marcha un plebiscito que permita al constituyente primario reformar la Constitución, potestad que hasta esa fecha hacía parte del Congreso como consecuencia de la reforma de $1957 .{ }^{65}$

A mediados de febrero toma forma esta iniciativa en lo que se dio a conocer como el "Acuerdo de la Casa de Nariño", ${ }^{66}$ en el cual los más altos dirigentes de los partidos políticos y otros sectores acordaron secundar al presidente en esta iniciativa. De este mismo acuerdo salió la Comisión Preparatoria de Reajuste Institucional. Esta era en realidad una de las propuestas más innovadoras de los últimos años en un país que reclamaba a gritos una modernización de orden político e institucional. Si bien la propuesta no tocaba las fibras más profundas de las elites políticas y económicas, sí mostraba al menos una ruta orientada hacia caminos diferentes por los cuales había transitado el Estado colombiano desde la fundación del Frente Nacional. Este acuerdo buscaba entonces refrendarse de forma democrática a través de un referéndum que tendría lugar en octubre de ese mismo año. La iniciativa del gobierno nacional despertó la atención y el entusiasmo de importantes sectores sociales y especialmente de las guerrillas, dado que, dentro de lo acordado, líderes designados de los movimientos armados podrían participar y ser escuchados en la conformación de las comisiones que estudiarían el dicho reajuste institucional. $\mathrm{Al}$ respecto se resalta que las FARC volvieron a establecer acercamientos con el gobierno y el M-19 decretó una tregua unilateral para estas semanas.

62 Un marco analítico y profundo de la situación política y social vivida lo presentan en diversas perspectivas Leal y Zamosc. Ver: Francisco Leal y León Zamosc, Al filo del caos: crisis politica en la Colombia de los años 1980 (Bogotá, Colombia: Tercer Mundo Editores, 1990).

63 Franco, 300.

64 Villarraga, 231.

65 Declaración del mando central del EPL: sí al plebiscito y a la asamblea constituyente, 15 de febrero de 1988; Declaración de las FARC: interés por el plebiscito y la reforma de la constitución, 15 de febrero de 1988.

66 “Crónica del parto constituyente", El Tiempo, 9 de diciembre de 1990, URL: http://www.eltiempo.com/ archivo/documento/MAM-33518. 
Pero el establishment, una vez más le jugaría una mala pasada a las instituciones, a la sociedad y a todos los actores implicados en el conflicto armado. El 4 de abril de 1988 el Consejo de Estado echó por el piso la iniciativa del gobierno declarando que iba en contra de los principios constitucionales. ${ }^{67}$ Esta situación jurídica y administrativa, que no sería desafortunadamente la última, deja en el vacío las propuestas del Ejecutivo y pone el proceso en un punto muerto. El M-19 que hasta esos días había llevado a cabo tímidos acercamientos con el gobierno, ante el fracaso de la propuesta de plebiscito se retracta de estos acercamientos y en contrapartida decreta lo que ellos denominaron una "guerra contra la oligarquía". ${ }^{68}$ Desde el punto de vista estratégico y militar, de parte del M-19 no había en realidad acciones serias que sugirieran nuevamente una reactivación de la guerra. Así, sus declaraciones iban más en lo retórico que en lo pragmático y para todo efecto práctico la tregua seguiría casi intacta.

Dentro de las excepciones a la tregua del M-19 se destaca un hecho que sin duda alguna marca un hito y un cambio representativo en el desarrollo de los acontecimientos. Como parte de la guerra a la oligarquía del "Eme" se destaca el secuestro efectuado al líder conservador Álvaro Gómez Hurtado ${ }^{69} \mathrm{el}$ domingo 29 de mayo de 1988, cuando este último salía de un oficio religioso en un sector del norte de Bogotá. ${ }^{70}$ Dentro de los análisis que podemos plantear desde un punto de vista histórico, es que los diálogos de paz de la administración Barco se dividen en dos a partir de este evento. Si en una primera mitad del gobierno, los acercamientos más intensos se manifestaron hacia las FARC, en la fase final de la presidencia será el M-19 quien tome el rol protagónico de la paz. El secuestro de Gómez se convirtió de algún modo en la nueva llave para presionar acercamientos entre la guerrilla y el gobierno. A pesar de que el M-19 era miembro pleno de la CGSB, sus acciones se realizaban por fuera del marco coordinado de esta organización. Una semana después del secuestro el "Eme" reconoce tener en su posesión a Gómez Hurtado y a un mes del rapto, la organización guerrillera expone desde la clandestinidad una suerte de pliego de peticiones que serán necesarias para liberar al secuestrado. ${ }^{71}$

67 Mauricio García Durán, De la Uribe a Tlaxcala: procesos de paz en Colombia (Bogotá, Colombia: CINEP, 1992), 101.

68 Pardo, 124.

69 Álvaro Gómez era uno de los miembros más representativos de la elite política conservadora en Colombia. Hijo del expresidente Laureano Gómez (1950-1953) y, a su vez, él mismo había sido candidato a la presidencia en años precedentes. Véase: http://www.banrepcultural.org/blaavirtual/biografias/hurtadoalvaro.htm.

70 “Álvaro Gómez es secuestrado por el M-19", El Espectador, 14 de julio de 2008, URL: https://www. elespectador.com/impreso/judicial/articuloimpreso-1988-alvaro-gomez-secuestrado-el-m-19.

71 García Durán, 105-106. 
Entre la guerra y la política. Una mirada comparativa de los procesos de paz en América Latina: los casos del FMLN y el M-19 (1986-1992)

\section{Fotografía 1 \\ "El retorno"}

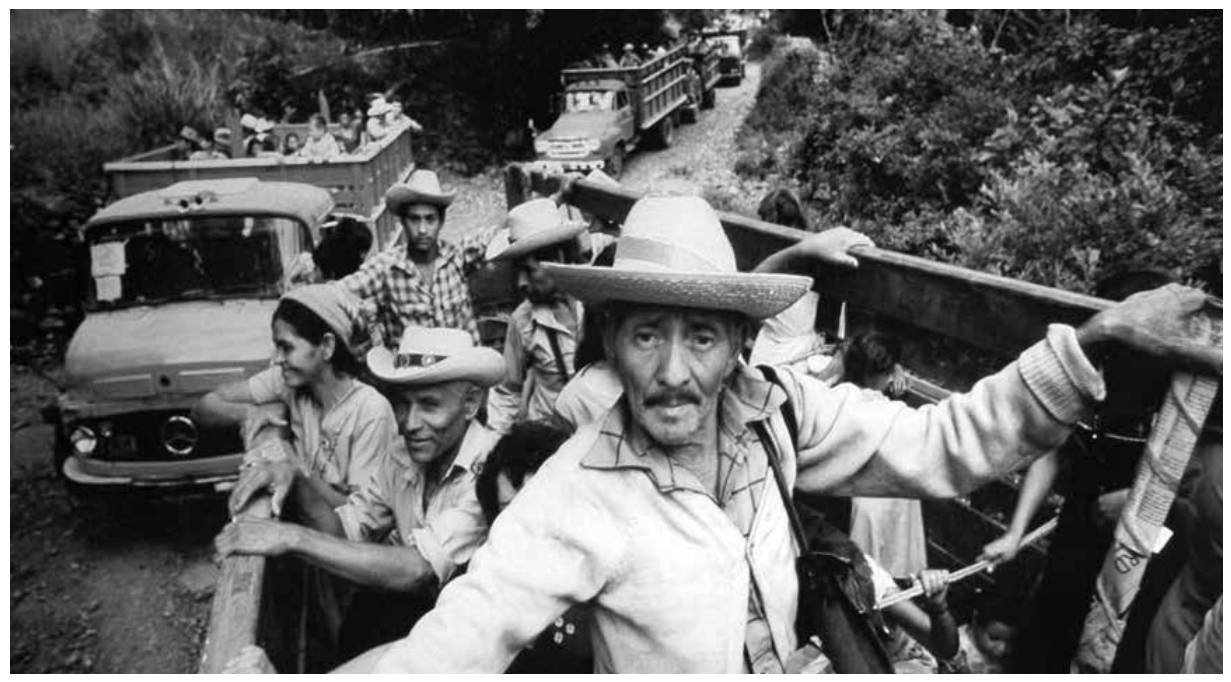

Fuente: "El retorno". Fototeca virtual del Museo de la Palabra y la Imagen, El Salvador. Imagen extraída de la colección "Guerra civil. El Salvador. Refugiados y retorno". Véase: http//museo. com.sv/fototeca/.

Estos puntos evidencian como de principio a fin la guerrilla del M-19 nunca abandonó el aspecto idealista y por ocasiones irreflexivo en torno a demandas que tenían más de forma que de fondo y que no apuntaban de manera directa a la consolidación de un cambio estructural que pudiera dar nuevas orientaciones al sistema político colombiano. Pero en medio de todo lo cierto era que al tener al excandidato Gómez en su poder, manejaban una poderosa llave de presión sobre el gobierno nacional. Dos semanas después de haber expuesto los once puntos por parte de la guerrilla y como consecuencia de acercamientos indirectos entre los rebeldes y el gobierno, se efectúa una reunión en la Nunciatura Apostólica de Ciudad de Panamá entre representantes de la sociedad civil y los partidos políticos y algunos delegados del M-19 liderados por Antonio Navarro. ${ }^{72}$ La razón para que el gobierno no participara de esta discusión era que tras un hecho reconocido como terrorista por parte de la guerrilla, el gobierno de Barco no pretendía dejarse coaccionar y acorralar bajo el chantaje. ${ }^{73}$ Como resultado de esta reunión emergen dos conclusiones significativas. La primera de ellas es la liberación de Gómez

72 Antonio Navarro era el segundo al mando en la organización del M-19. Luego de los múltiples asesinatos de líderes de esta guerrilla en años precedentes, él y Carlos Pizarro fueron, en la última fase, los comandantes de esta guerrilla. Para ver un perfil más preciso sobre este líder ver: http://lasillavacia.com/ quienesquien/perfilquien/antonio-navarro-wolff.

73 Marc Chernick, Un acuerdo posible: solución negociada al conflicto armado colombiano (Bogotá, Colombia: Aurora Editores, 2012), 115. 
Hurtado y la segunda -consecuencia de la primera- es realizar una cumbre en Bogotá invitando a amplios sectores - partidos, sindicatos, gremios e Iglesia, entre otros- con el ánimo de iniciar un diálogo nacional con miras a resolver la crisis de legitimidad por la que atravesaba el país. En efecto, el 20 de julio, fiesta nacional colombiana, es liberado Álvaro Gómez y nueve días después se realiza la que hoy se conoce como cumbre de Usaquén, liderada por la Iglesia católica. En esta cumbre no participó ningún delegado ni representante de las guerrillas, sin embargo, estas sí enviaron mensajes que fueron leídos en la jornada. ${ }^{74}$ Para todo efecto práctico la cumbre no tuvo un impacto representativo, pero se convierte en un precedente directo de lo que terminará siendo el proceso de paz con el M-19. De allí nace también la Comisión de Convivencia Democrática.

El gobierno de Barco presenta en ese marco la Iniciativa para la Paz el primero de septiembre. ${ }^{75}$ Este será el más importante antecedente que dará como resultado la desmovilización del M-19 un año y medio después. La Iniciativa de Barco, desarrollada por su consejero Pardo, planteaba un proceso progresivo de acercamiento con las guerrillas - de forma individual y no con el pleno de la CGSB-, en el cual a través del establecimiento de garantías de las dos partes se fuera creando un escenario de confianza que rindiera como fruto la desmovilización de las guerrillas. La propuesta comenzaba entonces por crear condiciones de distensión del conflicto y esta se debería reflejar por medio de treguas unilaterales por parte de los alzados en armas. Ante esta propuesta del gobierno las reacciones por parte de la guerrilla fueron variadas y notablemente pesimistas. En especial las FARC se mostraron renuentes ante una proposición que consideraban vacía y falta de sentido real de una comprensión de la situación política, económica y militar del momento. ${ }^{76}$ La Iniciativa para la Paz era considerada en pocas palabras como una farsa. De igual forma esta iniciativa se convertía en un claro y manifiesto desafío para la CGSB, dado que de allí se podía apreciar la capacidad de toma de decisiones colectivas y consensuadas. Y esta situación se va a comprobar rápidamente ya que será justamente el M-19 la organización que va a tomar serias consideraciones con respecto a la Iniciativa para la Paz del gobierno. Esta situación plantea desde ese momento serios quiebres internos de la CGSB y esto vendrá fuertemente derivado de las decisiones internas tomadas por el comandante de guerrilla, Carlos Pizarro. ${ }^{77}$

En diciembre de 1988 se da el primer encuentro entre Carlos Pizarro y Rafael Pardo y se convierte en la piedra angular del único proceso concreto y

74 Héctor Pineda, Miembro del M-19. Constituyente 1991. Entrevista con el autor, Bogotá, 12 de noviembre de 2015.

75 Alocución televisada del presidente Virgilio Barco: presentación de la iniciativa para la paz, 1 de septiembre de 1988.

76 Mario Aguilera, Guerrilla y población civil: trayectoria de las FARC (1949-2013) (Bogotá, Colombia: Centro Nacional de Memoria Histórica, 2015), 161.

77 Vera Grabe, La paz como revolución: M-19 (Bogotá, Colombia: Taller de Edición Rocca, 2017), 564. 
terminado de paz de la administración Barco. En ese encuentro se lanzan las primeras bases de lo que sería en el futuro el proceso de desarme y desmovilización de la guerrilla. En enero de 1989 continúan los acercamientos y las definiciones técnicas y metodológicas de lo que serán los diálogos. Las fuerzas armadas en Colombia, comandadas por el ministro Jaime Guerrero Paz, le daban su aval al proceso, lo cual era, en vista de los antecedentes, un buen síntoma para el proceso. Lo que vendrá en esas semanas es la definición de una agenda. ${ }^{78} \mathrm{La}$ consulta de los documentos que emanan de esas reuniones permite ver un grado de improvisación por parte de la guerrilla al no contar con una agenda concreta que se pudiera traducir en hechos tangibles y reales.

El tema que más circuló en los acercamientos entre el gobierno y la guerrilla era, sin duda alguna, la participación política de los reinsertados luego de un proceso de dejación de armas. Pero al lado de ello, y como consecuencia del contexto nacional, se hallaba el serio y grave problema del paramilitarismo. También se buscaban beneficios económicos para los excombatientes y una ley de indulto que les permitiera reinsertarse cómodamente a la vida civil. Dentro de los primeros acuerdos se llegó a la conclusión de la necesidad de una zona de distensión en la cual se pudieran concentrar las tropas guerrilleras. Quedó convenido entre Pardo y Pizarro que esa zona sería en Santo Domingo, Cauca. Allí se concentró el grueso de las tropas quedando un remanente en el norte del Huila bajo el mando de Marcos Chalita.

El año 1989 enmarcará en casi su totalidad los diálogos entre el gobierno y la guerrilla. A través de las denominadas Declaraciones Conjuntas hechas entre las partes podemos rastrear y apreciar de manera breve la evolución del proceso. El primer encuentro oficial entre las partes para dialogar tuvo lugar el 19 de enero. Allí, el comandante Pizarro llamó a los demás comandantes de la CGSB a unirse al proceso al cual estaba entrando el M-19. De igual forma se decretó la tregua unilateral por parte de la guerrilla y se planteó la necesidad de definir una agenda de negociaciones. También se rescata un hecho significativo para el proceso y es el llamado permanente que la guerrilla hace a la vinculación de los partidos políticos en el proceso. Esto denota claramente un objetivo final que se puede expresar a través de reformas constitucionales. ${ }^{79}$ De allí la importancia de que los partidos fueran parte activa de las negociaciones. Junto con ellos, la Iglesia y los militares también serán parte del proceso.

El segundo encuentro entre las partes tuvo lugar a inicios de febrero en Santo Domingo. Allí se seguían discutiendo la definición de una agenda y unos puntos concretos de trabajo. ${ }^{80}$ Un mes más tarde se realiza nuevamente otra reunión, esta vez en la Ciudad de México. El M-19 exigía en la reunión dar respuesta

78 Pardo, 137.

79 Primera declaración conjunta gobierno nacional - M-19, 19 de enero de 1989.

80 Segunda declaración conjunta gobierno nacional - M-19, 4 de febrero de 1989. 
urgente y real a las acciones de los paramilitares que vienen dando acciones de desaparición y asesinato de múltiples líderes de izquierda. ${ }^{81}$ Quince días después, en Santo Domingo, Cauca, se da de nuevo otra reunión entre las partes. Allí se producen avances considerables a través de la discusión de modo de reintegración de los alzados en armas, así como la definición de los representantes de las partes que participarían en las mesas de trabajo ${ }^{82}$ Estas mesas comenzarían a trabajar a partir del 5 de abril con base en las siguientes propuestas:

\section{Cuadro 1}

\section{Propuestas del gobierno de Barco y del M-19 a las mesas de trabajo}

\begin{tabular}{|c|c|}
\hline $\begin{array}{l}\text { PROPUESTAS EN LAS MESAS POR } \\
\text { PARTE DEL GOBIERNO }\end{array}$ & $\begin{array}{l}\text { PROPUESTAS EN LAS MESAS POR } \\
\text { PARTE DEL M-19 }\end{array}$ \\
\hline 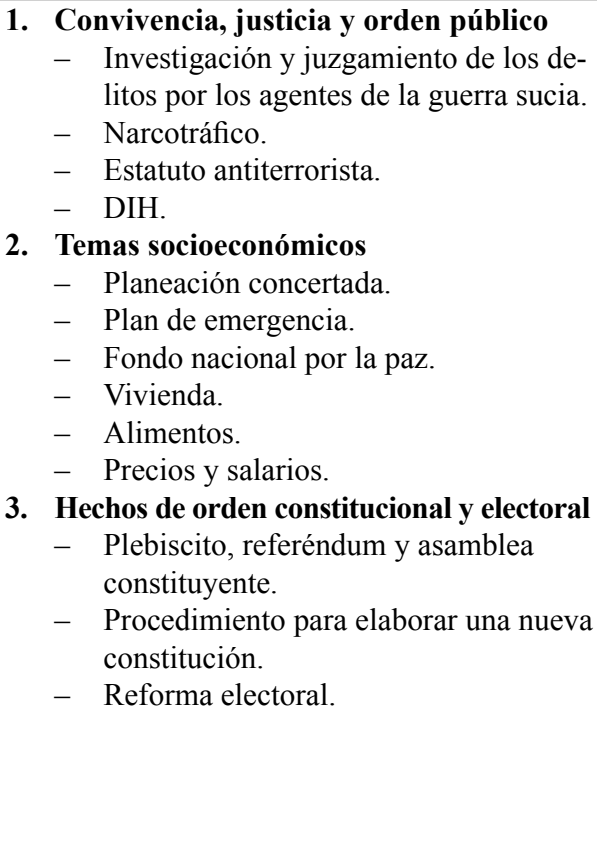 & $\begin{array}{l}\text { 1. Convivencia, justicia y orden público } \\
-\quad \text { Tribunal especial para investigar los } \\
\text { crímenes de los paramilitares. } \\
-\quad \text { Disolución de los grupos paramilitares. } \\
-\quad \text { Soluciones al problema del narcotráfico. } \\
-\quad \text { Derogación estatuto antiterrorista. } \\
- \text { DIH. } \\
\text { 2. Temas socioeconómicos } \\
-\quad \text { Ampliación del CONPES con partici- } \\
\text { - pación de la sociedad civil. } \\
-\quad \text { Programa de distribución de alimentos. } \\
-\quad \text { Aumento semestral del salario mínimo. } \\
-\quad \text { Consolidar un fondo nacional por la paz. } \\
\text { 3. Hechos de orden constitucional y electoral } \\
-\quad \text { Derogación del art. } 218 \text { de la Constitución. } \\
-\quad \text { Elaborar una nueva Constitución. } \\
-\quad \text { Plebiscito nacional para: } \\
\text { - Elección presidencial a dos vueltas. } \\
\text { - Sufragio obligatorio. } \\
\text { - Circunscripción electoral nacional. } \\
\text { - Financiación estatal de campañas }\end{array}$ \\
\hline
\end{tabular}

Fuente: Elaboración propia a partir del Plan de trabajo propuesto por el gobierno nacional para la mesa de trabajo, 3 de abril de 1989. Mensaje del comandante general del M-19 Carlos Pizarro a la mesa para la reconciliación nacional, 3 de abril de 1989.

En efecto, estamos hablando de agendas muy cercanas que no generaron mayores resistencias entre las partes. ${ }^{83}$

81 Tercera declaración conjunta gobierno nacional - M-19, 5 de marzo de 1989.

82 Cuarta declaración conjunta gobierno nacional - M-19, 17 de marzo de 1989.

83 Vale la pena señalar que temas como los de justicia transicional, Comisión de la Verdad, reforma a la Fuerza Armada, que se evidenciaron en El Salvador, no hacen parte de las demandas del M-19, tampoco son tenidas en cuenta por parte del gobierno de Barco. 
Entre la guerra y la política. Una mirada comparativa de los procesos de paz en América Latina: los casos del FMLN y el M-19 (1986-1992)

Las mesas trabajaron de forma regular durante tres meses. Al final de este trabajo se volvió a dar una reunión en Santo Domingo, Cauca, entre el gobierno y la guerrilla con el fin de analizar los avances dados por las mesas de trabajo. ${ }^{84}$ A finales de septiembre de 1989 la sexta reunión oficial de las partes abarca todo el resultado de las mesas de diálogo. Además de ello se comenzó a trabajar en el diseño de un plan nacional para la desmovilización. En este estadio las conversaciones estaban ya muy avanzadas y llegando a su recta final. ${ }^{85} \mathrm{El}$ gobierno de Barco había concertado previamente con los partidos políticos para la aprobación de una reforma constitucional que les diera piso a las demandas de la guerrilla en los puntos discutidos. Adicional a ello, en cuanto a la participación de desmovilizados, se creaba la circunscripción especial de paz que permitía a los antiguos combatientes participar con cierta favorabilidad en las elecciones de 1990 para Senado y Cámara de Representantes.$^{86}$ Dicho proyecto de reforma constitucional se convertía en la base de los acuerdos que debían terminar con la desmovilización total y el abandono de las armas de forma definitiva. Identificados los puntos nodales de la negociación el M-19 invita al gobierno y a los partidos políticos a vincularse en un Pacto Político que diera fiel cumplimiento a los acuerdos. De igual forma se discutía un plan de seguridad que pudiera garantizar la vida de los desmovilizados. Por último, se discutieron temas relativos a la ley de indulto y la conversión de la guerrilla en partido político. Lo que se creía el epílogo del proceso se consolida en la X Conferencia del M-19 que tuvo lugar, lógicamente, en Santo Domingo. Con una aplastante mayoría, el pleno de la guerrilla aprueba los acuerdos, la dejación de las armas y el reintegro a la vida civil. ${ }^{87}$

El 2 de noviembre, siete meses después de haber iniciado las negociaciones formales a partir de una agenda consolidada, se firma el Pacto Político por la Paz y la Democracia. Los tres ejes mencionados en el cuadro 1 conformarán este texto que abarca escasamente quince cuartillas englobando los acuerdos discutidos a lo largo del año. ${ }^{88}$ Una vez ratificado este Pacto solo quedaba la aprobación, casi segura, por parte del Congreso a finales del mes y el acto formal de dejación de las armas estaba programado para el 19 de diciembre. No obstante, en un acto inesperado, la reforma constitucional entra en crisis a partir del 30 de noviembre. A la reforma constitucional que buscaba abrirle camino a la paz y la desmovilización de la guerrilla se le quiso añadir un artículo en el cual se prohibía la extradición de nacionales por delitos cometidos en el extranjero. Esta acción, dada la coyuntura del narco terrorismo, tenía un claro tinte político-económico con plenas influencias del cartel de Medellín en el seno de los partidos políticos. El

84 Quinta declaración conjunta gobierno nacional - M-19, 18 de junio de 1989.

85 Sexta declaración conjunta gobierno nacional-M-19, 26 de septiembre de 1989.

86 Pardo, 140.

87 Comunicado del M-19: Décima conferencia nacional, Santo Domingo, Cauca, 5 de octubre de 1989.

88 Son sensibles las diferencias si tenemos en cuenta que el acuerdo de paz firmado entre el FMLN y el gobierno salvadoreño en 1992 abarcaba cerca de 200 páginas. 
gobierno de Barco se rehusaba a que la reforma fuera instrumentalizada de esta forma por un grupo de narcotraficantes que le había declarado la guerra al Estado y sus instituciones. De tal suerte, el mismo ejecutivo pidió hundir la reforma a inicios de diciembre. De esta forma se quedaba sin piso jurídico ni político el proceso casi finalizado con el M-19, lo que plantó los diálogos en su más seria crisis y la imposibilidad de efectuar la desmovilización en la fecha estipulada. ${ }^{89}$

Es así como a mediados de diciembre, en lugar de ultimar detalles del desarme, se tiene que realizar una nueva reunión entre el gobierno y la guerrilla para analizar la situación y encontrar alternativas. La respuesta de Pizarro es continuar con los objetivos propuestos a pesar de la adversidad. ${ }^{90}$ En realidad se trataba de una suerte de salto al vacío por parte de la guerrilla que continuaba en la dirección de entregar las armas sin ningún sustento jurídico-político y con pocas garantías reales de cumplimiento por parte del gobierno. En efecto, el M-19 se encontraba ante la disyuntiva de romper los diálogos y continuar la guerra o hacer un heroico acto de fe y continuar adelante. En caso de haber continuado la guerra, hubiera sido un escenario extremadamente complejo. Su campamento en Santo Domingo estaba resguardado por compañías del ejército bajo las órdenes del coronel Manuel José Bonnet. La guerrilla carecía de movilidad, piedra angular de todo movimiento guerrillero. Pero la situación no era solamente estratégica, sino política y económica. De acuerdo con Jaime Zuluaga, la guerrilla del M-19 entre 1985 y 1989 había entrado en una profunda crisis de orden organizacional. Políticamente había perdido s muy significativos desde la toma del palacio. Militarmente, el ejército le había asestado sendos golpes que afectaban su aparato y capacidad combativa. ${ }^{91}$ En ese marco, una salida hacia atrás era prácticamente improbable. Otra alternativa era apalancarse en la CGSB para corregir las fallas y suplir las falencias. Sin embargo, Pizarro a lo largo del proceso había demostrado las enormes distancias ideológicas y políticas con las otras guerrillas, lo cual hacía imposible esta salida. De tal suerte que en diciembre de 1989 el M-19 se encontraba presa de sí mismo y de la coyuntura. Es por ello que la decisión de continuar el proceso, a pesar de las múltiples amenazas, se plantea casi como la única alternativa. El gobierno no desaprovecha esta oportunidad y una vez terminadas las festividades de fin de año, en enero de 1990, otorga un indulto adelantado a Carlos Pizarro y Antonio Navarro con el fin de que estos hagan un intensivo trabajo político de forma bilateral con los partidos políticos, gremios, sectores sociales y desde luego con la sociedad en un año clave de elecciones. ${ }^{92}$ Algunas semanas después, el 9 de marzo de 1990, a

89 Pardo, 149.

90 Comunicado del M-19 ante el fracaso del referendo, aplazar las elecciones y convocar una asamblea nacional constituyente, 14 de diciembre de 1989.

91 Jaime Zuluaga, "De guerrillas a movimientos políticos. Análisis de la experiencia colombiana: el caso del M-19”, en: De las armas a la política, (eds.) Ricardo Peñaranda y Javier Guerrero (Bogotá, Colombia: IEPRI, Universidad Nacional de Colombia, 1999), 39.

92 Octava declaración conjunta gobierno nacional-M-19, 25 de enero de 1990. 
Entre la guerra y la política. Una mirada comparativa de los procesos de paz en América Latina: los casos del FMLN y el M-19 (1986-1992)

dos días de los comicios electorales, en un acto improvisado en Caloto, Cauca, se efectúa la ceremonia oficial de entrega de las armas que terminarán siendo fundidas en una siderúrgica en Cali.

La guerrilla del M-19 toma un nuevo rumbo e intentará explorar un nuevo camino sin experiencias previas que le puedan servir de lecciones aprendidas. Rápidamente se conformó el partido político Alianza Democrática M-19 que pasó por un éxito fugaz en los años de 1990 a 1992 entrando en una seria crisis en 1994. ${ }^{93}$ La desmovilización de esta guerrilla creó una profunda crisis al interior de la CGSB y las FARC calificaron de traidores a la causa al M-19. ${ }^{94}$ Para líderes como Jacobo Arenas y Manuel Marulanda, las acciones de Pizarro no denotaban algo más que una simple rendición. Lo cierto es que, en marzo de 1990, 781 militantes del M-19 abandonaron las armas y se reinsertaron a la vida civil tomando rumbos de las más diversas orientaciones.

\section{Conclusión: Miradas comparativas de los procesos de paz en el oca- so de la Guerra Fría}

En el desarrollo de las entrevistas realizadas en el marco de esta investigación, fueron recurrentes, especialmente por parte de los desmovilizados del FMLN, las menciones a la guerrilla del M-19. Era manifiesto, dentro de algunos líderes de la guerrilla salvadoreña, el conocimiento y aprecio de Jaime Bateman, al que casi todos manifestaban conocer y admirar. También fue manifiesto que el FMLN siguió muy de cerca el proceso vivido por el M-19 en Colombia para tomar nota de las posibles lecciones por aprender. El M-19 entrega oficialmente las armas quince días después de la derrota electoral de los sandinistas en Nicaragua, momento de gran crisis de las negociaciones entre el FMLN y el gobierno de Cristiani. De esta forma se puede decir que el caso del M-19, a excepción de los procesos de desmovilización de las guerrillas venezolanas en la década de 1960, es el primer caso exitoso de un proceso de desmovilización de una guerrilla por la vía de la negociación en América Latina. De allí es que reviste tanta importancia este tema de estudio. Si bien no existen dentro de los parámetros de negociaciones de paz, tiempos estipulados que puedan considerarse apropiados, resulta interesante que la negociación de paz en El Salvador haya tomado tan solo 22 meses, pero mejor aún, la negociación con el M-19 representó apenas la mitad del tiempo de los salvadoreños. En perspectiva internacional el proceso de paz de Irlanda tomó una década y el surafricano algo más de tres años. ${ }^{95} \mathrm{La}$

93 Carlo Nasi, Cuando callan los fusiles: impacto de la paz negociada en Colombia y Centroamérica (Bogotá, Colombia: Norma Editores, 2007), 107.

94 Eduardo Pizarro, Sociólogo, Universidad Nacional de Colombia. Hermano del comandante Carlos Pizarro. Entrevista con el autor, Bogotá, 28 de abril de 2016.

95 Miguel Barreto (ed.), Experiencias internacionales de paz (Bogotá, Colombia: Universidad Jorge Tadeo Lozano, 2016), 32. 
duración de los acuerdos sugiere de alguna forma la posición y radicalización de las partes en contienda, el capital político de estas y desde luego la presión de posibles actores internacionales. ${ }^{96}$ Ahora bien, nuestro interés en este breve espacio es dilucidar algunas cuestiones que nos lleven a comprender las dinámicas vividas por estas dos guerrillas latinoamericanas. Resulta importante, en primer lugar, saber por qué estas guerrillas llegan a la decisión de desmovilizarse. ${ }^{97}$ Para comenzar a responder esta pregunta nos apoyamos en una apreciación de la comandante del ERP y negociadora de la paz Ana Guadalupe Martínez:

"aquí en El Salvador vivimos la guerra de una forma muy intensa, los combates eran cotidianos y el asedio de las partes permanente. La economía estaba paralizada por las acciones de la guerrilla y la población sufría enormemente. Había un hastío, todos queríamos la paz, no había otra alternativa. Pero la paz que queríamos era la paz en medio de un país modernizado y que ampliara las vías de la participación política para el conjunto de sus ciudadanos". ${ }^{98}$

Es así como podemos ir acercándonos a la respuesta a nuestro cuestionamiento inicial. La intensidad de la guerra entre 1980 y 1991 fue tal que todas las partes anhelaban la paz. Cierto, algunos sectores como los militares y los partidos de extrema derecha se negaban a la negociación y a un cambio estructural del país, dado que el modelo establecido les convenía mucho. ${ }^{99}$ Para 1989, llega a la presidencia un líder emergente del partido que habían fundado los empresarios y los sectores radicales de los militares representados en el mayor Roberto D'Aubuisson. El mismo Cristiani pertenecía a las familias acaudalas del país que habían hecho dinero en el negocio de la banca.

La paz era un estadio necesario para todas las partes. El empresariado del que hemos hablado se vio seriamente afectado como consecuencia del constante sabotaje a la infraestructura, pero también las amenazas a la producción por parte de la guerrilla. El aspecto militar, primera alternativa que tuvieron en mente para derrotar a la guerrilla, había fracasado. La ofensiva de noviembre de 1989 fue clave en esa concepción. A pesar de la ayuda de los Estados Unidos, no fue posible derrotar a la guerrilla. No había una mínima cercanía a dicha derrota.

96 Vincent Fisas, Cultura de paz y gestión de conflicto (Barcelona, España: Icaria Editorial, 2002).

97 A este respecto se abre un interesante marco de análisis del cual algunos autores han tratado de abordar a través de la idea de la elección racional y de los costos y beneficios que representan tanto las negociaciones como los posteriores procesos de desmovilización. En ese orden de ideas, tanto los gobiernos como los grupos rebeldes evalúan los costos que requiere hacer la paz al igual que los beneficios. Para las guerrillas puede ser un costo dejar las armas, pero también puede implicar el beneficio de la participación política. Para los gobiernos es un costo tolerar a los reinsertados, pero a su vez, en términos de economía y de impacto en la opinión pública, se abren múltiples beneficios. Ver: Matthew Shugart, "Guerrillas and Elections: An Institutionalist Perspective on the Costs of Conflict and Competition", International Studies Quarterly (EE. UU.) 36, n. 2 (junio, 1992): 121-151, DOI: http://dx.doi.org/10.2307/2600878.

98 Ana Guadalupe Martínez, entrevista con el autor.

99 Roberto Cañas, entrevista con el autor. 
Entre la guerra y la política. Una mirada comparativa de los procesos de paz en América Latina: los casos del FMLN y el M-19 (1986-1992)

Dentro de las filas de la guerrilla también había una fatiga producto del asedio de la fuerza armada y una guerra que si bien la habían sabido plantear en diferentes planos que incluían el desarrollo de un poder dual y una correcta articulación con amplios sectores de la sociedad -campesinos, estudiantes, obreros, desempleados y amas de casa, por mencionar solo algunos-, no tenían la garantía de poderla ganar. ${ }^{100}$ Es muy probable que el desarrollo militar y la capacidad de combate fueran el objetivo buscado para sentarse a una mesa de negociaciones con argumentos políticos y militares. Así poder ser escuchados y que sus planteamientos fueran tenidos en cuenta con el fin de llevar a cabo las reformas de fondo que se pedían: "En El Salvador tuvo que haber una guerra y haber derramado tristemente mucha sangre para poder modernizar y democratizar el país. Ese fue en gran parte el sentido de esa trágica guerra". ${ }^{101}$ A pesar de que la paz era el estadio más deseado por el conjunto de los salvadoreños, es de resaltar la escasa participación, manifestación y movilización de la sociedad civil exigiendo cese a las hostilidades. El ambiente de guerra intenso y la polarización de la misma sociedad impedían una movilización coordinada que pudiera tener un impacto del orden político. Por último, como ya se ha mencionado, existe un factor del orden internacional que también contribuye con la comprensión del porqué las partes se sientan a negociar. El final de la Guerra Fría anunciaba de entrada que los apoyos para los dos bandos podrían ser retirados de manera brusca. Si bien el FMLN no dependía tanto del apoyo soviético, la ayuda nicaragüense y cubana sustentaban en gran medida su accionar. Con la salida de Ortega del poder en febrero de 1990, la ecuación tendía a ser aún más compleja para los insurgentes. ${ }^{102}$ Por su parte, también se ha mencionado, que los Estados Unidos eran el principal soporte económico de la guerra salvadoreña. Quien alentó esa guerra decididamente fue Ronald Reagan, pero la decisión de George Bush fue dejar de alimentar una guerra que no había llegado a ningún resultado concreto. A través del Departamento de Estado, la Casa Blanca presionó en varias ocasiones la necesidad y diríamos obligatoriedad de negociar la paz con la guerrilla.

En lo que concierne al caso colombiano encontramos que no existe en realidad un empate militar del nivel presentado en El Salvador. En primera medida el FMLN como bloque guerrillero era superior en hombres y armas al M-19 desde lo individual. La intensidad de los combates era menor en Colombia en términos de guerrillas. ${ }^{103}$ Recordemos que antes de sentarse a negociar, la guerrilla del FMLN asestó sendos golpes que incluyeron la toma de la capital por cuatro días, lo cual ponía en evidencia una fortaleza del orden militar. Para el caso del M-19 -aparte del secuestro de Álvaro Gómez-no se registran acciones

100 Binford Leigh.

101 Salvador Samayoa, entrevista con el autor.

102 Alain Rouquié, Guerras y Paz en América Central (México, D.F.: FCE, 1994), 302.

103 Es necesario decir que entre los años de la administración Barco (1986-1990) era más preocupante la acción armada y terrorista de los narcotraficantes que de parte de las mismas guerrillas. Véase: Francisco Leal y León Zamosc, Al filo del caos... 
de orden militar a lo largo de 1988. Esta organización no está en capacidad de amenazar el establecimiento, mucho menos pensar en la toma armada de una ciudad.

Entonces lo que podemos concluir es que el FMLN salvadoreño negocia la paz por una fuerte presión internacional, pero también por una exigencia de las elites económicas al gobierno Cristiani y un hastío general provocado por la guerra civil. La guerrilla del FMLN se apalancó en actos militares de gran envergadura para utilizar esto como músculo político que fue fundamental en el pulso que se desarrolló con el gobierno salvadoreño. En Colombia la negociación de paz con el M-19 tiene antecedentes serios como el fracaso de las negociaciones de Betancur y su clausura con la toma del Palacio de Justicia. Desde el punto de vista militar el M-19 no puede ser comparado con sus congéneres salvadoreños. Una vez que se iniciaron los diálogos el 10 de enero de 1988 el "Eme" nunca se levantó de la mesa, habiendo muchas provocaciones para ello. Lo que sugieren las evidencias es que esta guerrilla padecía de una fatiga organizacional e institucional fruto de las políticas internas que más bien nos hablan de una cierta indisciplina y flexibilidad ante diversas situaciones que otras organizaciones más rigurosas como las FARC nunca toleraron. ${ }^{104}$ Entonces, el M-19 se encontraba en cierta medida acorralado militarmente, desgastado físicamente y seriamente afectado ante la ausencia de s notables que mantuvieran la moral de la organización. Así, el M-19 careció del músculo político que le sobró al FMLN.

Si se hace una comparación entre la agenda propuesta por el FMLN en Caracas en mayo de 1990 y los acuerdos aprobados en México en enero de 1992 encontramos pocas diferencias. Lo cual sugiere que el FMLN fue hábil en la negociación y supo imponer sus criterios. Se llegó al final a un acuerdo de siete puntos generales en un documento de fondo en el que se aprobaron discusiones y que se desarrollaba en 70 páginas. El acuerdo con el M-19 se expresa en cerca de 15 páginas alrededor de tres puntos generales. ${ }^{105}$

Tanto para el FMLN como para el M-19 la reforma constitucional se planteaba como un tema medular dentro de las negociaciones. Sin reforma los salvadoreños no hubieran continuado la negociación y fue realmente la presión de los Estados Unidos la que puso a andar las reformas a mediados de 1991. En el caso colombiano hemos visto como la debilidad institucional obligó a hundir la

104 Mario Aguilera, "Claves y distorsiones del régimen disciplinario guerrillero", Análisis Político (Colombia) 79 (2013): 45-62, URL: https://revistas.unal.edu.co/index.php/anpol/article/view/43581/44872.

105 A este respecto resulta interesante el planteamiento de Garibay. Su tesis radica en que las negociaciones entre el gobierno salvadoreño y el FMLN se basaron en un rediseño institucional. Esta fórmula abrió paso para que la antigua guerrilla se consolidar como opción política y como partido en aras de recoger el sentimiento de amplios sectores de la población para un rediseño del marco económico y social del país. Esto no va a suceder en Colombia como consecuencia de una negociación, a su juicio, apresurada con claros tintes de rendición. Ver: David Garibay, "De la lutte armée à la lutte electorale, itineraires divergents d'une trajectoire insolite. Une camparaison à partir des cas cetroamerican et colombien", Revue Internationale d'Études Comparées (Francia) 12, n. 3 (2005): 283-297, DOI: http://dx.doi.org/10.3917/ripc.123.0283. 
Entre la guerra y la política. Una mirada comparativa de los procesos de paz en América Latina: los casos del FMLN y el M-19 (1986-1992)

reforma constitucional por intervención de las mafias del narcotráfico. Aun así, sin reforma, el M-19 da un salto al vacío y lleva a cabo la desmovilización, algo impensable en el esquema de negociación salvadoreño.

Ahora bien, si miramos la esencia de las negociaciones y de los acuerdos encontramos que para ambas organizaciones era de suma importancia el tema de la participación política con garantías. ${ }^{106}$ En el caso salvadoreño es claro que la principal pretensión es la apertura de los espacios políticos. Pero se entiende además la importancia de la reforma militar vinculando un cambio en la doctrina de las fuerzas armadas y una reestructuración a fondo de estas. Además de ello se peleó de forma intensa por la desarticulación de los cuerpos paramilitares y los escuadrones de la muerte. Esto no hacía parte de las demandas del M-19 y se erige como una diferencia de gran importancia. A pesar de que se manifestaron las inconformidades y advertencias en relación con los grupos paramilitares colombianos no se diseñaron estrategias desde los acuerdos para luchar contra este flagelo y nunca se desarrolló la mínima discusión de reforma militar. De hecho y como es sabido, en la década de 1990 el fenómeno se multiplicó de forma alarmante en el país.

Otro de los aspectos que más sobresale en las negociaciones de El Salvador es que la guerrilla del FMLN utilizaba el cese al fuego como mecanismo de negociación. Siempre fue la gran demanda del gobierno de Cristiani, la de negociar a partir del cese al fuego. El FMLN se negó a esta demanda y logró prorrogarla hasta dos semanas después de la firma final de los acuerdos en Chapultepec. Para el caso colombiano encontramos que la condición sine qua non para desarrollar las negociaciones fue justamente la tregua. Al ser el M-19 la única organización que puso en marcha dicha tregua, fue la única organización con la cual avanzaron los diálogos con el gobierno de Barco poniendo sobre la mesa la capacidad política de negociación frente a la del M-19.

$\mathrm{Si}$ se da una mirada profunda a las dos agendas propuestas en las dos negociaciones se pueden hallar ciertos lugares comunes, tales como la participación política, la reforma constitucional, la reforma electoral y los cambios en los aspectos socioeconómicos. Como se ha señalado, la gran ausencia de las negociaciones con la guerrilla colombiana fue la reforma militar. En ambos casos resultó ser el tema socio económico una tarea pendiente. Dentro de los acuerdos y la agenda de negociación, la parte del modelo económico-social se remitió a dos aspectos centrales: una reforma agraria y una mención, un poco tímida por cierto, hacia la protección de la sociedad salvadoreña del modelo neoliberal que

106 Para Hensell y Gerdes el tema de la conversión a partidos políticos fruto de procesos de negociación de paz resulta casi natural. En su óptica, la lógica de las negociaciones es llegar a ser partidos políticos, una segunda opción puede ser la vinculación a fuerzas armadas o de seguridad. La exclusión de estos campos puede simplemente traducirse en un retorno a la guerra. Véase: Stephan Hensell y Felix Gerdes, "Exit From War: The Transformation of Rebels into Post-War Power Elites", Security Dialogue (EE. UU.) 48, n. 2 (diciembre, 2017): 168-84, DOI: http://dx.doi.org/10.1177/0967010616677713. 
se anunciaba para la región latinoamericana en esos años. ${ }^{107} \mathrm{Al}$ fin de cuentas ninguno de estos dos aspectos prosperó. La tierra, fiel bastión de las elites cafeteras, azucareras y algodoneras de El Salvador, y base de la riqueza de sus elites, fue un aspecto difícil de reestructurar. Los informes que la ONUSAL le remitía en 1992 y 1993 al Secretario General de Naciones Unidas, Butros-Ghali, nos sugieren como estos temas fueron poco atendidos. ${ }^{108}$ Una de las misiones centrales de la ONUSAL, creada por los acuerdos de San José en julio de 1990, era la verificación del cumplimiento de los compromisos allí firmados. ${ }^{109}$ Su tarea, luego del 16 de enero de 1992 era hacer un seguimiento al cumplimiento de lo acordado por las partes. Regularmente la ONUSAL le daba informes al Secretario y este, a su vez, rendía informe al Consejo de Seguridad. Dentro de los informes se evidencia como fue necesario prorrogar en tres ocasiones la existencia de la ONUSAL - que terminaría sus funciones en mayo de 1995-, dado que existían pruebas de incumplimiento a los acuerdos de 1992. Entre los factores que más se resaltan están, pues, el tema de la tierra, el modelo de reforma agraria y los temas sociales. Eran los puntos en los cuales definitivamente no había progresos. De hecho, la ONUSAL dio por terminada su tarea en El Salvador, sin haber detectado cambios sensibles en la materia. Ana Guadalupe Martínez señala al respecto que: "fue un grave error no haber destinado más tiempo y energía a aspectos fundamentales como el tema económico y social", ${ }^{110}$ a lo que quisiéramos añadir la visión de Óscar Santamaría: "en la mesa de negociaciones no estábamos para negociar un modelo económico y social, sino para negociar la desmovilización con garantías de la guerrilla. Si querían ellos modificar dicho modelo, tendrían que hacerlo a través de las urnas en el juego político de las elecciones y la toma del poder por la vía democrática". ${ }^{111}$ Así pues, constatamos que las negociaciones de inicios de la década de 1990 en El Salvador están marcadas por un componente altamente militar que absorbió gran parte de las energías y del tiempo de los negociadores en la búsqueda de la paz.

La propuesta económica del M-19 incluía algunos elementos que a la postre terminarían consignados en la Constitución de 1991, tales como la planeación participativa. Adicional a ello se incluían exigencias como los salarios de los trabajadores urbanos, mejores condiciones para los campesinos, la protección de la oferta agrícola y de los recursos naturales, la seguridad alimentaria, la vivienda y la salud. No obstante, estas intenciones caerían en el vacío no solo por el fracaso de la reforma constitucional colombiana en diciembre de 1989, sino por la llegada imperante del modelo neoliberal que justamente buscaba disponer de

107 Carmen Villacorta, “Transición a la democracia electoral y neoliberalismo en El Salvador”, en: Historia sobre el conflicto armado y sus secuelas, (ed.) Jorge Juárez (San Salvador, Fundación FES, 2014), 65.

108 Véase: http://www.un.org/es/peacekeeping/missions/past/onusal.htm.

109 Óscar Martínez, Las negociaciones de los acuerdos de paz, 157-169.

110 Ana Guadalupe Martínez, entrevista con el autor.

111 Óscar Santamaría, entrevista con el autor. 
medidas contrarias a lo pensado por el M-19. Así, ante la llegada de este modelo económico a América Latina, tenemos tal vez una de las pocas similitudes entre los dos procesos y acuerdos de paz: el rotundo fracaso de las reformas económicas y sociales, base histórica del desarrollo de los conflictos armados en la región.

En cuanto al papel de la comunidad internacional encontramos amplias diferencias entre los dos procesos. Como se ha demostrado, en el caso salvadoreño el rol de los Estados Unidos y de las Naciones Unidas fue simplemente fundamental y su inexistencia hubiera implicado sin duda alguna más años de confrontación. Las Naciones Unidas y en especial su Secretario General fueron mediadores que manifestaron las más altas calidades para destrabar el proceso con amplia habilidad diplomática. En Colombia, no solo en el gobierno de Barco, sino en los demás procesos de paz, se ha denotado una particularidad y es justamente un rol más tangencial de la comunidad internacional. Ha sido una tendencia que Chernick califica de errónea, dado que el Estado colombiano ha sido durante las diferentes negociaciones de paz juez y parte. ${ }^{12}$ Esta no sería la situación salvadoreña en la cual se contó con un verdadero y legítimo árbitro. Ahora bien, la ausencia de la comunidad internacional durante los acuerdos entre Barco y el M-19 no implicó el fracaso de estos. Lo cual sugiere la fragilidad y debilidad y tal vez improvisación de dichos acuerdos en términos de capacidad política de negociación de las partes.

Por último, resulta interesante resaltar que en ambos procesos los tiempos electorales, políticos y administrativos terminaron siendo factores claves al seno de las negociaciones. Tanto los timing legislativos en El Salvador como en Colombia contaban para el desarrollo de las negociaciones. Lo hemos podido apreciar con el caso de las reformas de abril de 1991 en el país centroamericano y la prisa por una reforma constitucional a finales de 1989 en Colombia. De igual forma, se evidenció una desmovilización de la guerrilla del M-19 a tan solo dos días de las elecciones locales que revestían tanta importancia. Estas maratones que implican las negociaciones políticas ponen especialmente en evidencia la importancia de los aspectos electorales en las negociaciones de paz entre guerrillas y gobiernos y demarcan una finalidad específica dentro de los dos casos aquí estudiados.

Lo cierto es que tanto el FMLN como el M-19 firmaron la paz en medio de circunstancias particulares para cada uno de los países y de los gobiernos vigentes. Ambos soñaron con la consolidación de una democracia y tal vez ambos vieron frustrados esos sueños. En materia política el FMLN se convirtió en partido político dos años después de haber firmado la paz y de forma

112 Marc Chernick, 153. 
progresiva y exponencial se convirtió en un partido exitoso. ${ }^{113}$ Para el año 2000 había conquistado la mayoría de diputados en el Congreso y en el 2009 accedía a la cabeza del Ejecutivo. ${ }^{114}$ En cuanto al M-19 encontramos más bien una dinámica opuesta que estuvo rodeada de una euforia política y electoral en los primeros meses posteriores a la desmovilización, pero que fue perdiendo rápidamente su dinámica política. La falta de claridad de su posición ideológica y la tendencia a convertirse en un partido tipo "atrapa todo" condenaron su futuro político y su capital electoral. ${ }^{115}$

113 Álvaro Artiga-González, Gobernabilidad y democracia en El Salvador (San Salvador, El Salvador: PNUD, 2007).

114 Nasi, 115.

115 Zuluaga, 57. 